\section{(6) OPEN ACCESS}

\title{
Haemodynamic effects of riociguat in inoperable/ recurrent chronic thromboembolic pulmonary hypertension
}

\author{
Nick H Kim, ${ }^{1}$ Andrea M D'Armini, ${ }^{2}$ Friedrich Grimminger, ${ }^{3,4}$ Ekkehard Grünig, ${ }^{5}$ \\ Marius M Hoeper, ${ }^{4,6}$ Pavel Jansa, $^{7}$ Eckhard Mayer, ${ }^{8}$ Claus Neurohr, ${ }^{9}$ \\ Gérald Simonneau, ${ }^{10}$ Adam Torbicki, ${ }^{11}$ Chen Wang, ${ }^{12}$ Arno Fritsch, ${ }^{13}$ Neil Davie, ${ }^{13}$ \\ Hossein-Ardeschir Ghofrani ${ }^{3,4,14}$
}

For numbered affiliations see end of article.

\section{Correspondence to} Dr Nick H Kim, Division of Pulmonary and Critical Care Medicine, University of California, San Diego, 9300 Campus Point Drive, MC 7381, La Jolla, CA 92037, USA; h33kim@ucsd.edu

Received 9 March 2016 Revised 14 September 2016 Accepted 19 September 2016 Published Online First 23 December 2016

CrossMark

\section{To cite: $\mathrm{Kim} \mathrm{NH}$,}

D'Armini AM, Grimminger $F_{\text {, }}$ et al. Heart 2017;103:599606.

\section{ABSTRACT}

Objective We compared the haemodynamic effects of riociguat in patients with inoperable chronic thromboembolic pulmonary hypertension (CTEPH) or persistent/recurrent CTEPH after pulmonary endarterectomy in the Chronic Thromboembolic Pulmonary Hypertension Soluble Guanylate CyclaseStimulator Trial 1 study.

Methods Patients with inoperable or persistent/ recurrent CTEPH ( $n=261$; mean \pm SD age $59 \pm 14$ years; $66 \%$ women) were randomised to riociguat (up to $2.5 \mathrm{mg}$ three times daily) or placebo. Haemodynamic parameters were assessed at baseline and week 16 . Results Riociguat decreased pulmonary vascular resistance (PVR) in inoperable $(n=189$; least-squares mean difference: -285 dyn s/ $\mathrm{cm}^{5}(95 \% \mathrm{Cl}-357$ to $-213) ; p<0.0001)$ and persistent/recurrent $(n=72$; -131 dyn $\mathrm{s} / \mathrm{cm}^{5}$ (95\% Cl -214 to -48$) ; p=0.0025$ ) patients. Cardiac index improved in inoperable patients by a least-squares mean difference of $+0.6 \mathrm{~L} / \mathrm{min} / \mathrm{m}^{2}$ (95\% Cl 0.4 to $0.7 ; \mathrm{p}<0.0001)$, while in persistent/ recurrent patients the change was $+0.2 \mathrm{~L} / \mathrm{min} / \mathrm{m}^{2}(95 \%$ $\mathrm{Cl}-0.1$ to $0.5 ; \mathrm{p}=0.17)$. Mean pulmonary artery pressure decreased in inoperable and persistent/recurrent patients $(-4.7 \mathrm{~mm} \mathrm{Hg}(95 \% \mathrm{Cl}-6.9$ to -2.6 ; $p<0.0001$ and $-4.8 \mathrm{~mm} \mathrm{Hg}(-8.2$ to $-1.5 ; p=0.0055)$,

respectively). For all patients, changes in 6 min walk distance correlated with changes in PVR $(r=-0.29$ (95\% $\mathrm{Cl}-0.41$ to -0.17$) ; \mathrm{p}<0.0001)$ and cardiac index ( $r=0.23$ (95\% Cl 0.10 to 0.35$) ; p=0.0004)$.

Conclusions Riociguat improved haemodynamics in patients with inoperable CTEPH or persistent/recurrent CTEPH.

Trial registration number NCT00855465.

\section{INTRODUCTION}

Chronic thromboembolic pulmonary hypertension $(\mathrm{CTEPH})$ is a chronic, life-threatening disease associated with significant morbidity and mortality. ${ }^{1}$ The disease is characterised by the obstruction of pulmonary vasculature by residual organised thrombi, ${ }^{2}$ which if left untreated, leads to the development of pulmonary hypertension (PH), progressive right ventricular (RV) dysfunction and ultimately death. ${ }^{3} 4$

Pulmonary endarterectomy (PEA) is the gold standard treatment for CTEPH and the only available therapy that has the potential to cure the disease. ${ }^{5-7}$ However, some patients may be deemed inoperable due to the occlusion of distal vessels, existing comorbidities that increase the risks of surgery, lack of access to expert surgical centres or patient refusal for surgery. ${ }^{5}{ }^{8-10}$ Furthermore, approximately 5\%-35\% of patients have persistent/ recurrent $\mathrm{PH}$ after PEA. ${ }^{11-14}$ Until recently there were no approved pharmacotherapies to treat some of these patients, ${ }^{6}$ specifically those deemed technically inoperable due to distal disease and patients with persistent $\mathrm{PH}$ following PEA. Previous randomised controlled studies of pulmonary arterial hypertension (PAH)-targeted medications in patients with inoperable CTEPH have shown variable clinical efficacy. ${ }^{15} 16$

Riociguat is the first member of the soluble guanylate cyclase (sGC) stimulator class of therapeutic agents. ${ }^{17-20}$ It has a dual mode of action: sensitising $\mathrm{sGC}$ to endogenous nitric oxide (NO) by stabilising NO-sGC binding and directly stimulating sGC independently of $\mathrm{NO}$ via a different binding site. ${ }^{19}{ }^{20}$ In the phase III Chronic Thromboembolic Pulmonary Hypertension Soluble Guanylate Cyclase-Stimulator Trial 1 (CHEST-1) study, riociguat improved $6 \mathrm{~min}$ walk distance (6MWD) and a range of secondary end points, including pulmonary vascular resistance (PVR), $\mathrm{N}$-terminal prohormone of brain natriuretic peptide (NT-proBNP) levels and WHO functional class in patients with CTEPH. ${ }^{21}$ Based on these results, riociguat is, to date, the only pharmacotherapy approved for the treatment of inoperable or persistent/recurrent CTEPH. ${ }^{6} 722$

Here we present a detailed analysis of the haemodynamic data from the CHEST-1 study in subgroups of patients with inoperable CTEPH or persistent/recurrent $\mathrm{PH}$ after PEA.

\section{METHODS}

\section{Study population}

The CHEST-1 study methodology has been published previously. ${ }^{21}$ Patients with CTEPH who were adjudicated to be technically inoperable or had persistent/recurrent $\mathrm{PH}$ after PEA were eligible if they had a 6MWD of 150-450 m, PVR >300 dyn s/cm and mean pulmonary artery pressure (mPAP) $\geq 25 \mathrm{~mm} \mathrm{Hg}$. Patients who received an endothelin 
receptor antagonist, prostacyclin analogue, phosphodiesterase type 5 inhibitor or NO donor within the 3 months before study entry were not eligible for the study.

Patients with CTEPH who were considered inoperable by study investigators underwent prospective adjudication by an adjudication committee (nominated by the sponsor) composed of six experienced PEA surgeons. A local decision was permitted in cases where an experienced surgeon collaborated with the study centre in the context of the patient's regular diagnostic workup. Technical inoperability, based on previously published criteria, ${ }^{6}{ }^{23}$ was determined using at least a pulmonary angiogram supplemented by a ventilation-perfusion (VQ) scan (as the preferred method) or alternatively a CT pulmonary angiogram (minimum 64-slice spiral CT with contrast medium) supplemented by a VQ scan. Medical history and haemodynamic data (at least mean right atrial pressure (RAP), mPAP, PVR, cardiac output and pulmonary artery wedge pressure (PAWP)) were also provided.

The research protocol was approved by local ethics committees and written informed consent was obtained from patients in accordance with the Declaration of Helsinki. The study is registered at ClinicalTrials.gov (identifier NCT00855465).

\section{Study design}

CHEST-1 was a 16-week, double-blind, randomised, placebocontrolled, multicentre study conducted in 89 centres across 26 countries between February 2009 and June 2012. An interactive voice-response system and a computer-generated random code (provided by Bayer Randomisation Management) were used to randomly assign patients in a 1:2 ratio to placebo or oral riociguat administered at doses that were individually adjusted for each patient up to $2.5 \mathrm{mg}$ three times daily. During the initial 8 weeks of the study, the dose of riociguat was adjusted every 2 weeks according to an individual plan based on the patient's systolic blood pressure (SBP) and signs or symptoms of hypotension. From a starting dose of $1 \mathrm{mg}$ three times daily, the dose of riociguat was increased (by $0.5 \mathrm{mg}$ three times daily) if trough SBP was $\geq 95 \mathrm{~mm} \mathrm{Hg}$; maintained if SBP was $90-94 \mathrm{~mm} \mathrm{Hg}$ and decreased (by $0.5 \mathrm{mg}$ three times daily) if SBP was $<90 \mathrm{~mm} \mathrm{Hg}$ without symptomatic hypotension. The dose reached at the end of the 8 -week adjustment phase was considered to be the optimal dose for the individual patient and was continued for a further 8 weeks.

Randomised patients were seen at baseline and at weeks 2, 4, 6, 8, 12 and 16. Haemodynamic parameters were assessed by right heart catheterisation (RHC) (Swan Ganz catheterisation and thermodilution methodology) at baseline and week 16 .

\section{Outcome measures}

The primary outcome of CHEST-1 was the change in 6MWD from baseline to week $16 .^{21}$ Secondary outcomes included the changes from baseline to week 16 in PVR, NT-proBNP and WHO functional class and time to clinical worsening. Exploratory outcomes included the change from baseline to week 16 in a range of additional haemodynamic parameters, including RAP, PAWP, cardiac output and mixed venous oxygen saturation $\left(\mathrm{SvO}_{2}\right)$. Calculated haemodynamic parameters, determined using standard formulas, included mean arterial pressure (MAP), mPAP, PVR, systemic vascular resistance (SVR), pulmonary diastolic pressure gradient (DPG) and cardiac index. Adverse events (AEs) and laboratory variables were assessed throughout the study and during the safety follow-up period.

\section{Statistical analysis}

The statistical analysis plan for CHEST-1 has been published previously. ${ }^{21}$ The changes from baseline to week 16 in haemodynamic parameters, 6MWD and NT-proBNP were analysed by analysis of covariance, followed by a test of normality of the residuals and a non-parametric-stratified Wilcoxon test on rejection. Predefined analysis of the changes in 6MWD and post hoc analysis of the changes in haemodynamic parameters in the inoperable and post-PEA subgroups was undertaken using the same methods. The interaction between change from baseline to week 16 in the inoperable and persistent/recurrent subgroups was assessed using analysis of covariance. A Spearman's ranked correlation was used to determine the correlation between

Table 1 Baseline demographics for the overall group and the inoperable and persistent/recurrent PH following PEA subgroups

\begin{tabular}{|c|c|c|c|c|c|c|}
\hline \multirow[b]{2}{*}{ Characteristic } & \multicolumn{2}{|l|}{ Inoperable CTEPH } & \multicolumn{2}{|c|}{ Persistent/recurrent PH following PEA } & \multicolumn{2}{|l|}{ All patients } \\
\hline & Riociguat $(n=121)$ & Placebo $(n=68)$ & Riociguat $(n=52)$ & Placebo $(n=20)$ & Riociguat $(n=173)$ & Placebo $(n=88)$ \\
\hline Female sex, n (\%) & $86(71)$ & $45(66)$ & $32(62)$ & $9(45)$ & $118(68)$ & $54(61)$ \\
\hline \multicolumn{7}{|l|}{ Race, n (\%) } \\
\hline White & $76(63)$ & $49(72)$ & $44(85)$ & $16(80)$ & $120(69)$ & $65(74)$ \\
\hline Black & $5(4)$ & 0 & $2(4)$ & $1(5)$ & $7(4)$ & $1(1)$ \\
\hline Asian & $32(26)$ & $17(25)$ & $5(10)$ & $3(15)$ & $37(21)$ & $20(23)$ \\
\hline Multiple & $1(1)$ & 0 & 0 & 0 & $1(1)$ & 0 \\
\hline Not reported & $7(6)$ & $2(3)$ & $1(2)$ & 0 & $8(5)$ & $2(2)$ \\
\hline Mean age (SD), years & $59(14)$ & $60(12)$ & $60(14)$ & $57(15)$ & $59(14)$ & $59(13)$ \\
\hline Mean BMI (SD), kg/m² & $27(5)$ & $28(5)$ & $28(7)$ & $28(6)$ & $27(6)$ & $28(5)$ \\
\hline \multicolumn{7}{|l|}{ WHO FC, n (\%)* } \\
\hline 1 & $2(2)$ & 0 & $1(2)$ & 0 & $3(2)$ & 0 \\
\hline$\|$ & $38(31)$ & $18(26)$ & $17(33)$ & $7(35)$ & $55(32)$ & $25(28)$ \\
\hline III & $75(62)$ & $49(72)$ & $32(62)$ & $11(55)$ & $107(62)$ & $60(68)$ \\
\hline IV & $6(5)$ & $1(1)$ & $2(4)$ & $1(5)$ & $8(5)$ & $2(2)$ \\
\hline Missing & 0 & 0 & 0 & $1(5)$ & 0 & $1(1)$ \\
\hline Mean 6MWD (SD), $\mathrm{m}$ & $335(83)$ & $351(75)$ & $360(78)$ & $374(72)$ & $342(82)$ & $356(75)$ \\
\hline
\end{tabular}

*Data may not add up to $100 \%$ due to rounding.

6MWD, 6 min walk distance; BMI, body mass index; CTEPH, chronic thromboembolic pulmonary hypertension; PEA, pulmonary endarterectomy; PH, pulmonary hypertension; WHO FC, WHO functional class. 


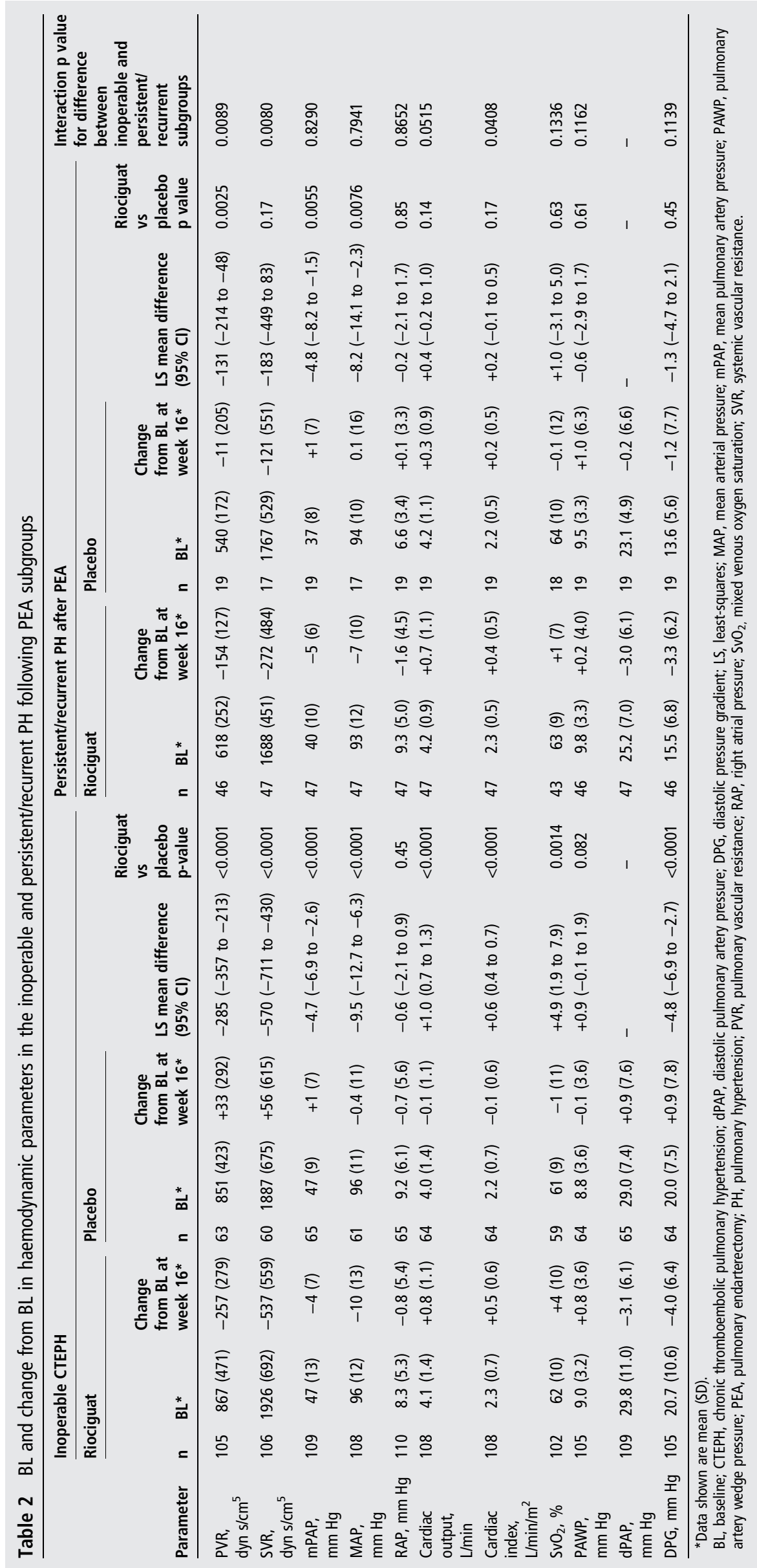


change in 6MWD and change in PVR and cardiac index at week 16.

Missing values for haemodynamic parameters and NT-proBNP, where the patient died or withdrew from the study, were imputed according to the last post-baseline measurement. In the case of withdrawal with no post-baseline measurements, the baseline value was used. In the case of $6 \mathrm{MWD}$, the last observed value was taken, except in cases of death or clinical worsening without a termination visit, where worst values $(0 \mathrm{~m})$ were imputed.

AEs during the study period included all AEs that started or worsened from the time of administration of the first dose of the study drug until 2 days after the administration of the last dose.

\section{RESULTS}

\section{Baseline demographics and haemodynamics}

Patient characteristics were well balanced between the groups at baseline and the majority of patients had WHO functional class II or class III symptoms (table 1). There were more patients in the inoperable CTEPH subgroup $(n=189)$ compared with the persistent/recurrent PH following PEA subgroup $(n=72)$. The 6MWD was marginally higher at baseline in patients with persistent/recurrent PH following PEA than in those patients with inoperable CTEPH (table 1). Baseline haemodynamic values in the overall study population were characteristic of a general CTEPH population and included elevated PVR and mPAP (table 2). ${ }^{8}$ However, haemodynamic impairments were slightly less severe in the persistent/recurrent PH after PEA subgroup at baseline compared with the inoperable CTEPH subgroup (table 2). Patient disposition in CHEST-1 has been published previously. ${ }^{21}$

\section{Dosing}

In the riociguat treatment group, $77 \%$ of patients were receiving the maximum dose of riociguat $(2.5 \mathrm{mg}$ three times daily) at week $16,12 \%$ of patients were receiving $2.0 \mathrm{mg}$ three times daily, $6 \%$ of patients were receiving $1.5 \mathrm{mg}$ three times daily, $4 \%$ of patients were receiving $1.0 \mathrm{mg}$ three times daily and $1 \%$ of patients were receiving $0.5 \mathrm{mg}$ three times daily.

\section{Haemodynamic parameters}

In the overall population, riociguat significantly improved a range of haemodynamic parameters at week 16 compared with placebo. PVR significantly decreased in the riociguat group $(-29 \%)$ compared with placebo $(+3 \%)$ by a least-squares (LS)

$$
\begin{aligned}
& + \text { Arithmetic mean } \\
& \text { Outlier }
\end{aligned}
$$

\section{Overall population}

$-246 \mathrm{dyn} \cdot \mathrm{s} \cdot \mathrm{cm}^{-5}$

(95\% Cl: -303 to $-190 ; p<0.0001$ )

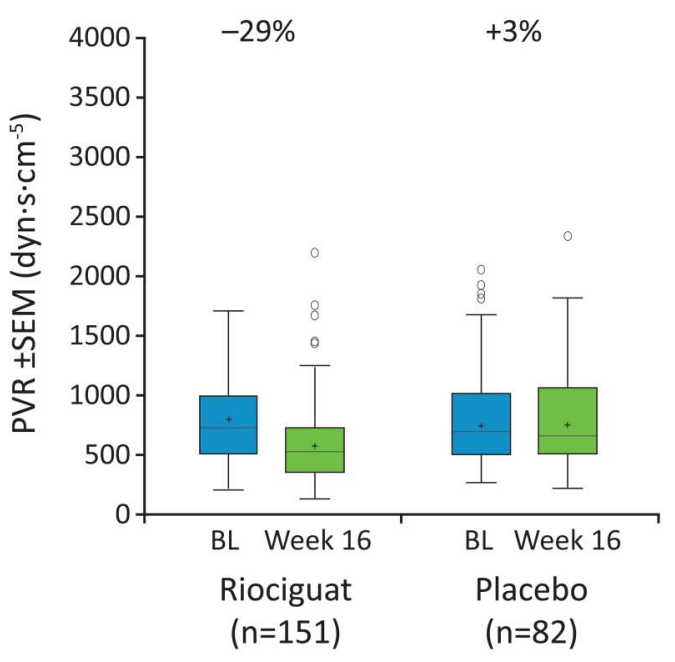

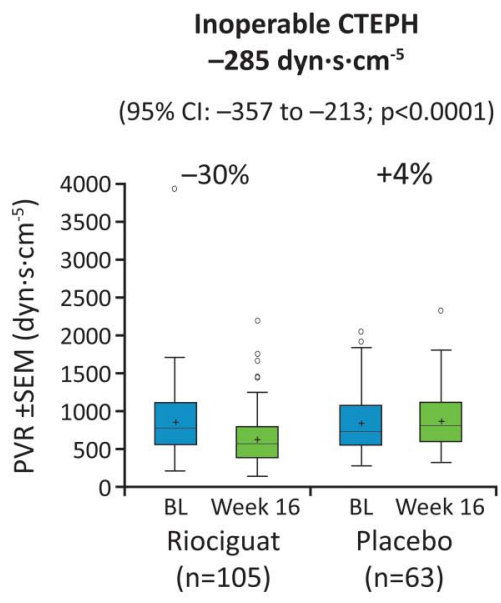

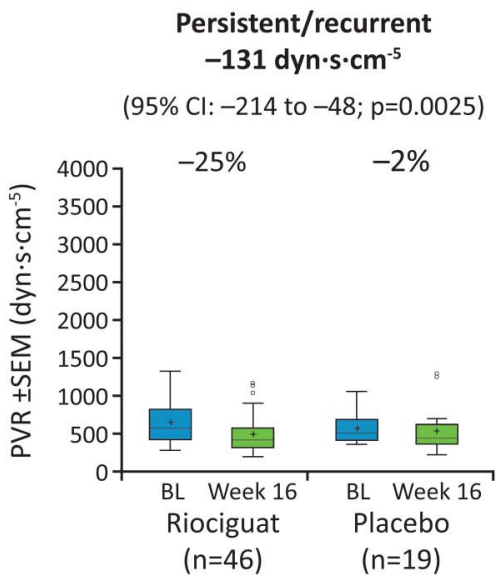

Figure 1 Boxplots for pulmonary vascular resistance (PVR) at baseline (BL) and CHEST-1 week 16 in the overall population and the inoperable CTEPH and persistent/recurrent PH after PEA subgroups. LS mean treatment effect $(95 \% \mathrm{Cl})$ was determined using ANCOVA. Box: 25th to 75 th percentile; horizontal line: median; cross: arithmetic mean; vertical lines extend from the box to a distance of at most $1.5 \mathrm{IQRs}$; percentages refer to change from baseline in arithmetic mean. Outliers are plotted separately. ANCOVA, analysis of covariance; CHEST-1, Chronic Thromboembolic Pulmonary Hypertension Soluble Guanylate Cyclase-Stimulator Trial 1;CTEPH, chronic thromboembolic pulmonary hypertension; LS, least-squares; PEA, pulmonary endarterectomy; $\mathrm{PH}$, pulmonary hypertension. 
mean difference of $246 \mathrm{dyn} \mathrm{s} / \mathrm{cm}^{5}$ (95\% CI -303 to -190 ; $\mathrm{p}<0.0001$ ) (figure 1). Cardiac index significantly increased in the riociguat group $(+20 \%)$ versus placebo $(-<1 \%)$ by an LS mean difference of $0.5 \mathrm{~L} / \mathrm{min} / \mathrm{m}^{2} \quad(95 \%$ CI 0.3 to 0.6 ; $\mathrm{p}<0.0001$ ) (figure 2). Significant changes were also observed in SVR $\quad(\mathrm{p}<0.0001), \quad$ mPAP $\quad(\mathrm{p}<0.0001), \quad$ cardiac output $(\mathrm{p}<0.0001), \quad \mathrm{SvO}_{2} \quad(\mathrm{p}=0.001), \quad \mathrm{MAP} \quad(\mathrm{p}<0.0001), \quad$ dPAP $(\mathrm{p}=0.0002)$ and DPG $(\mathrm{p}<0.0001)$. RAP and PAWP did not show relevant elevations at baseline and were unchanged at week 16. Mean \pm SD SBP decreased in the riociguat arm by -10 $\pm 14 \mathrm{~mm} \mathrm{Hg}$ (from $119 \pm 15 \mathrm{~mm} \mathrm{Hg} ; \mathrm{n}=173$ ), whereas in the placebo group mean \pm SD SBP decreased by $-5 \pm 15 \mathrm{~mm} \mathrm{Hg}$ (from $123 \pm 16 \mathrm{~mm} \mathrm{Hg}$ at baseline; $\mathrm{n}=88$ ). No clinically relevant changes in heart rate were observed during the study; in the riociguat group, mean $\pm \mathrm{SD}$ heart rate was $78 \pm 12 \mathrm{bpm}$ at baseline and $79 \pm 11 \mathrm{bpm}$ at week 16 ; in the placebo group, mean \pm SD heart rate was $76 \pm 12 \mathrm{bpm}$ and $78 \pm 13 \mathrm{bpm}$ at baseline and week 16 , respectively. Mean \pm SD arterial oxygen saturation decreased from baseline to week 16 by $1.5 \pm 4.4 \%$ in the riociguat group $(\mathrm{n}=152)$ and by $3.1 \pm 8 \%$ in the placebo group $(\mathrm{n}=80)$.
The haemodynamic improvements with riociguat in the inoperable CTEPH and persistent/recurrent PH after PEA subgroups were largely consistent with the results from the overall population (table 2; figures 1 and 2). There were significant changes in PVR, SVR, mPAP, cardiac output, cardiac index, $\mathrm{SvO}_{2}$ and MAP in the inoperable CTEPH subgroup, while in the persistent/ recurrent $\mathrm{PH}$ after PEA subgroup, there were significant changes in PVR, mPAP and MAP. Diastolic pulmonary artery pressure also improved at week 16 in both subgroups with riociguat compared with placebo (table 2). Improvements in PVR, cardiac output, cardiac index, mPAP and DPG were generally greater in the inoperable CTEPH subgroup than the persistent/recurrent PH after PEA subgroup (table 2; figures 1 and 2); however, the relative changes in these parameters in riociguat-treated patients were similar between the inoperable CTEPH subgroup and persistent/recurrent PH after PEA subgroup: cardiac output $(+21 \%$ vs $+18 \%$, respectively), cardiac index $(+21 \%$ vs $+17 \%$, respectively), mPAP ( $-9 \%$ vs $-12 \%$, respectively) and DPG $(-19 \%$ vs $-21 \%$, respectively). An analysis of covariance for the interaction between change from baseline to week 16 in inoperable and persistent/recurrent subgroups showed significant
+ Arithmetic mean Outlier
Inoperable CTEPH

$+0.6 \mathrm{~L} / \mathrm{min} / \mathrm{m}^{2}$

(95\% Cl: 0.4 to $0.7 ; p<0.0001)$

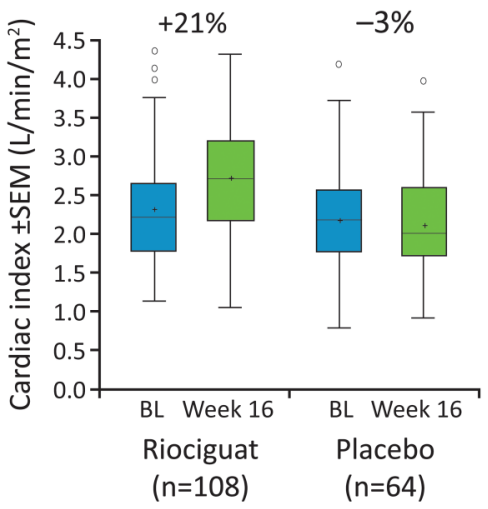

Persistent/recurrent

$+0.2 \mathrm{~L} / \mathrm{min} / \mathrm{m}^{2}$

( $95 \% \mathrm{Cl}:-0.1$ to $0.5 ; p=0.17$ )

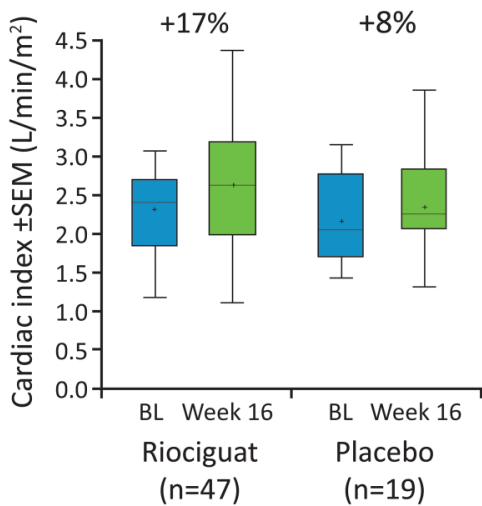

Figure 2 Boxplots for cardiac index at baseline (BL) and CHEST-1 week 16 in the overall population and the inoperable CTEPH and persistent/ recurrent PH after PEA subgroups. LS mean treatment effect $(95 \% \mathrm{CI})$ was determined using ANCOVA. Box: 25th to 75th percentile; horizontal line: median; cross: arithmetic mean; vertical lines extend from the box to a distance of at most 1.5 IQRs; percentages refer to change from baseline in arithmetic mean. Outliers are plotted separately. ANCOVA, analysis of covariance; CHEST-1, Chronic Thromboembolic Pulmonary Hypertension Soluble Guanylate Cyclase-Stimulator Trial 1; CTEPH, chronic thromboembolic pulmonary hypertension; LS, least-squares; PEA, pulmonary endarterectomy; $\mathrm{PH}$, pulmonary hypertension. 
differences in PVR, SVR and cardiac index $(p=0.0089,0.0080$ and 0.0408 , respectively; table 2).

\section{Effect on other end points}

Riociguat significantly improved the primary end point, change from baseline in 6MWD at week 16, in the overall population by an LS mean difference versus placebo of +46 m (95\% CI 25 to $67 \mathrm{~m} ; \mathrm{p}<0.0001$ ) (figure 2). The changes in 6MWD at week 16 were $+54 \mathrm{~m}(95 \%$ CI 29 to $78 \mathrm{~m})$ in the inoperable CTEPH subgroup and $+26 \mathrm{~m}(95 \% \mathrm{CI}-16$ to $68 \mathrm{~m})$ in the persistent/ recurrent $\mathrm{PH}$ after PEA subgroup.

In the overall population, changes in 6MWD correlated weakly with changes in PVR $(\mathrm{r}=-0.29 ; 95 \%$ CI -0.41 to $-0.17 ; \mathrm{p}<0.0001)$ and cardiac index $(\mathrm{r}=0.23 ; 95 \%$ CI 0.10 to $0.35 ; \mathrm{p}=0.0004$ ) (figure 3 ). The correlation coefficient between 6MWD and PVR was $-0.11 \quad(95 \%$ CI -0.23 to 0.01 ; $\mathrm{p}=0.0795)$ at baseline and, for 6MWD versus cardiac index at baseline, it was 0.14 (95\% CI 0.02 to 0.26 ; $p=0.0226)$. The correlation coefficient between 6MWD and PVR was -0.20 (95\% CI -0.32 to $-0.07 ; \mathrm{p}=0.0021$ ) at week 16 and, for $6 \mathrm{MWD}$ versus cardiac index at week 16 , it was $0.20(95 \% \mathrm{CI}$ 0.07 to $0.32 ; \mathrm{p}=0.0020$ ).

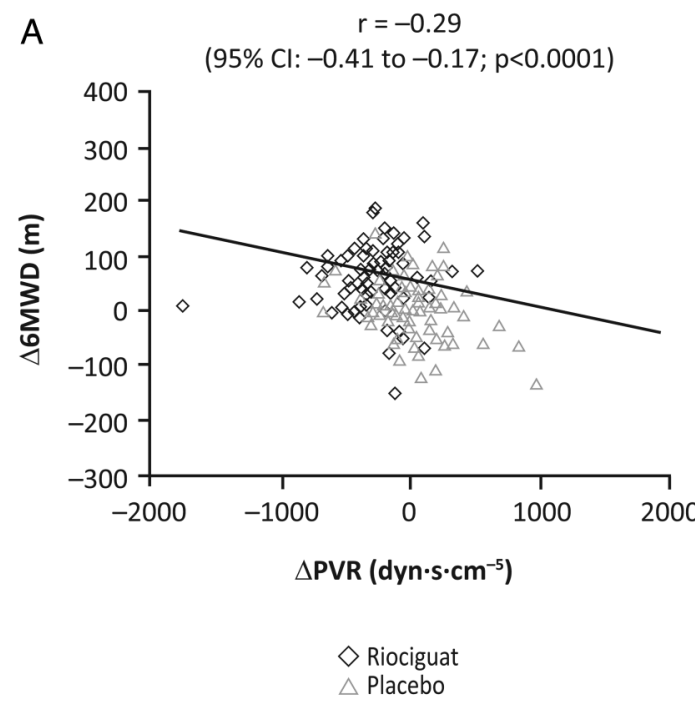

B (95\% Cl: 0.10 to $0.35 ; p=0.0004)$

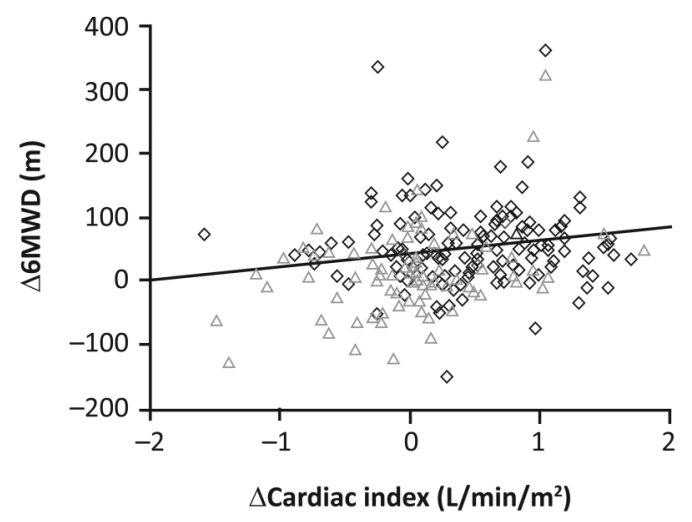

Figure 3 Correlation scatter plots showing change from baseline to week 16 in (A) 6MWD and PVR and (B) 6MWD and cardiac index. Correlation was assessed using a Spearman's rank analysis. The line of best fit was determined using a linear regression analysis. 6MWD, 6 min walk distance; PVR, pulmonary vascular resistance.
Table 3 Adverse events occurring in more than $5 \%$ of patients in any group

\begin{tabular}{|c|c|c|c|c|}
\hline \multirow[b]{2}{*}{ Adverse event, n (\%) } & \multicolumn{2}{|l|}{ Inoperable } & \multicolumn{2}{|c|}{$\begin{array}{l}\text { Persistent/recurrent } \\
\text { PH following PEA }\end{array}$} \\
\hline & $\begin{array}{l}\text { Riociguat } \\
(n=121)\end{array}$ & $\begin{array}{l}\text { Placebo } \\
(n=68)\end{array}$ & $\begin{array}{l}\text { Riociguat } \\
(n=52)\end{array}$ & $\begin{array}{l}\text { Placebo } \\
(n=20)\end{array}$ \\
\hline Any & $108(89)$ & $61(90)$ & $51(98)$ & $15(75)$ \\
\hline Dizziness & $27(22)$ & $8(12)$ & $12(23)$ & $3(15)$ \\
\hline Headache & $26(21)$ & $8(12)$ & $17(33)$ & $4(20)$ \\
\hline Dyspepsia & $20(17)$ & $6(9)$ & $11(21)$ & $1(5)$ \\
\hline Peripheral oedema & $17(14)$ & $15(22)$ & $10(19)$ & $3(15)$ \\
\hline Nasopharyngitis & $14(12)$ & $6(9)$ & $12(23)$ & $2(10)$ \\
\hline Hypotension & $13(11)$ & $3(4)$ & $3(6)$ & 0 \\
\hline Diarrhoea & $11(9)$ & $3(4)$ & $6(12)$ & $1(5)$ \\
\hline Nausea & $9(7)$ & $6(9)$ & $10(19)$ & $1(5)$ \\
\hline $\begin{array}{l}\text { Upper respiratory tract } \\
\text { infection }\end{array}$ & $9(7)$ & $3(4)$ & $1(2)$ & $1(5)$ \\
\hline Vomiting & $8(7)$ & $2(3)$ & $9(17)$ & $1(5)$ \\
\hline Increased INR & $8(7)$ & $4(6)$ & $2(4)$ & 0 \\
\hline Prolonged aPTT & $7(6)$ & $2(3)$ & $1(2)$ & 0 \\
\hline Cough & $6(5)$ & $11(16)$ & $3(6)$ & $5(25)$ \\
\hline Dyspnoea & $6(5)$ & $9(13)$ & $2(4)$ & $3(15)$ \\
\hline Urinary tract infection & $6(5)$ & 0 & $1(2)$ & $2(10)$ \\
\hline Abdominal discomfort & $6(5)$ & 0 & 0 & $2(10)$ \\
\hline Back pain & $5(4)$ & $5(7)$ & $2(4)$ & 0 \\
\hline Chest pain & $5(4)$ & $4(6)$ & $2(4)$ & 0 \\
\hline Flushing & $4(3)$ & $2(3)$ & $3(6)$ & 0 \\
\hline $\begin{array}{l}\text { Gastro-oesophageal reflux } \\
\text { disease }\end{array}$ & $4(3)$ & 0 & $3(6)$ & 0 \\
\hline Hypokalaemia & $3(2)$ & $2(3)$ & $4(8)$ & 0 \\
\hline Extremity pain & $3(2)$ & $5(7)$ & 0 & 0 \\
\hline Hyperkalaemia & $3(2)$ & 0 & 0 & $2(10)$ \\
\hline Palpitations & $2(2)$ & $2(3)$ & $4(8)$ & $2(10)$ \\
\hline Insomnia & $2(2)$ & $5(7)$ & $2(4)$ & $1(5)$ \\
\hline Muscle spasms & $1(1)$ & $2(3)$ & $3(6)$ & 0 \\
\hline Respiratory tract infection & $1(1)$ & 0 & $3(6)$ & $1(5)$ \\
\hline Hyperhidrosis & $1(1)$ & $2(3)$ & 0 & $2(10)$ \\
\hline Increased blood creatinine & 0 & $4(6)$ & $3(6)$ & $1(5)$ \\
\hline Oropharyngeal pain & 0 & 0 & $3(6)$ & 0 \\
\hline
\end{tabular}

\section{Safety}

Detailed safety data from the CHEST-1 study have been published previously. ${ }^{21}$ There were no differences in AEs between the inoperable and persistent/recurrent subgroups (table 3). AEs specific to the RHC procedure were infrequent; in the overall population, two patients $(1 \%)$ in the riociguat group experienced an $\mathrm{AE}$ of catheter-site haemorrhage compared with no such events in the placebo group.

\section{DISCUSSION}

In the Phase III CHEST-1 study, riociguat significantly improved a range of haemodynamic variables in patients with CTEPH, including PVR, mPAP, cardiac index and $\mathrm{SvO}_{2}$. These haemodynamic improvements were generally observed in both patients with inoperable CTEPH and those with persistent/recurrent $\mathrm{PH}$ after PEA. In the overall study population, a small yet significant correlation was observed between the change in 6MWD and the change in haemodynamic variables (PVR and cardiac index). These results complement the primary end point of 
improvements in exercise capacity with riociguat in the CHEST-1 study, together with improvements in a range of secondary end points including NT-proBNP and WHO functional class. $^{21}$

To date, the CHEST-1 study represents the largest and most detailed haemodynamic characterisation of patients with inoperable CTEPH or persistent/recurrent PH after PEA at baseline and after targeted therapy. The improvements in PVR, mPAP, cardiac index and $\mathrm{SvO}_{2}$ in the overall population were observed without relevant changes in heart rate and were largely consistent in patients with inoperable CTEPH and those with persistent/recurrent PH after PEA. Patients in the persistent/recurrent PH after PEA subgroup of CHEST-1 showed numerically lower improvements from baseline to week 16; however, they had a lower PVR and higher 6MWD at baseline compared with patients in the inoperable subgroup. Nevertheless, the relative changes in PVR, mPAP, cardiac index and $\mathrm{SvO}_{2}$ were comparable between the two subgroups and 6MWD increased to similar levels between the two subgroups $(379 \mathrm{~m}$ and $387 \mathrm{~m}$ in patients with inoperable and persistent/recurrent $\mathrm{PH}$ after PEA, respectively).

Haemodynamic parameters are objective indicators of the status of the pulmonary circulation, with reports indicating that PVR, mPAP, RAP and cardiac index are predictive of outcome in patients with CTEPH. ${ }^{11} 2425$ Whether the acute effects of riociguat on haemodynamics translate into long-term benefits for patients with inoperable CTEPH or persistent/recurrent $\mathrm{PH}$ following PEA is unknown. Currently, the long-term extension study CHEST-2 is actively monitoring safety and durability of clinical parameters over an extended period beyond the original 16 weeks of the CHEST-1 study. ${ }^{26}$

The broader impact of haemodynamic improvements with riociguat requires further characterisation. In the primary analysis of the CHEST-1 study, the changes in PVR, mPAP, $\mathrm{SvO}_{2}$ and cardiac index were accompanied by a significant decrease in NT-proBNP, ${ }^{21}$ which has been shown to be a biomarker of RV function and an indicator of prognosis. ${ }^{8}$ Furthermore, haemodynamic improvements correlated with improvements in 6MWD in the present analysis. These complementary data demonstrate the value of measuring improvements across multiple parameters in order to more fully evaluate disease severity and better understand the effect of a given treatment.

Riociguat demonstrated efficacy in both 6MWD and PVR in patients with CTEPH. Previous trials of PAH-targeted therapies for the treatment of patients with CTEPH have had variable results. ${ }^{15} 16$ PEA is still the recommended therapy for patients with operable CTEPH as it represents the only potentially curative option. ${ }^{6} 7$ Therefore, all patients with suspected CTEPH should always be referred to an expert centre for confirmation of diagnosis, assessment of operability and surgical treatment if

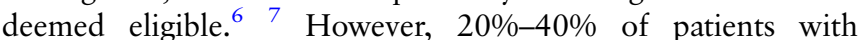
CTEPH may be considered inoperable or have persistent/recurrent CTEPH after PEA and are candidates for medical treatment. $^{6727}$

\section{Limitations}

There were several limitations in the CHEST-1 study. Although the analyses of the inoperable CTEPH and persistent/recurrent $\mathrm{PH}$ after PEA subgroups were pre-specified, statistical testing of the haemodynamic data in these subgroups was performed post hoc, although using the same statistical methods as the prespecified subgroup analyses for 6MWD. Moreover, the CHEST-1 study was not powered to detect statistically significant differences in subgroups. The data presented are for
16 weeks of riociguat therapy and long-term haemodynamic measurements were not planned. Therefore, future studies will need to determine if the haemodynamic changes at week 16 correlate with long-term clinical outcome.

\section{CONCLUSION}

In summary, riociguat improved a range of haemodynamic variables in both patients with inoperable CTEPH and patients with persistent/recurrent PH after PEA in CHEST-1 and improvements were comparable between the subgroups. In the overall population, improvements in PVR and cardiac index correlated with increases in $6 \mathrm{MWD}$. These results emphasise the efficacy of riociguat in the CHEST-1 study, adding to the previously reported improvements in exercise capacity and other clinically relevant parameters.

\section{Key messages}

\section{What is already known on this subject?}

In the Chronic Thromboembolic Pulmonary Hypertension Soluble Guanylate Cyclase-Stimulator Trial 1 (CHEST-1) study, treatment with riociguat significantly improved exercise capacity and a range of clinically relevant end points in patients with chronic thromboembolic pulmonary hypertension (CTEPH).

\section{What might this study add?}

This study adds a detailed comparison of the haemodynamic data from the inoperable and persistent/recurrent CTEPH subgroups in CHEST-1. Riociguat decreased pulmonary vascular resistance (PVR) in inoperable (least-squares mean difference: -285 dyn $\left.\mathrm{s} / \mathrm{cm}^{5} ; \mathrm{p}<0.0001\right)$ and persistent/recurrent (-131 dyn s/cm $; p=0.0025)$ patients and improved several other haemodynamic parameters. Overall, changes in $6 \mathrm{~min}$ walk distance correlated with changes in PVR and cardiac index.

\section{How might this impact on clinical practice?}

Taken together with the results of the CHEST- 1 study, these data confirm the beneficial haemodynamic effects of riociguat in patients with inoperable and persistent/recurrent CTEPH and demonstrate the value of measuring improvements across multiple parameters to better understand the effects of treatment.

\section{Author affiliations}

${ }^{1}$ Division of Pulmonary and Critical Care Medicine, University of California, San Diego, La Jolla, California, USA

${ }^{2}$ Division of Cardiothoracic Surgery, Foundation "I.R.C.C.S. Policlinico San Matteo", University of Pavia School of Medicine, Pavia, Italy

${ }^{3}$ University of Giessen and Marburg Lung Center (UGMLC), Giessen, Germany

${ }^{4}$ German Center of Lung Research (DZL), Giessen, Germany

${ }^{5}$ Center for Pulmonary Hypertension, Thoraxclinic, University Hospital Heidelberg,

Heidelberg, Germany

${ }^{6}$ Clinic for Respiratory Medicine, Hannover Medical School, Hannover, Germany ${ }^{7}$ Clinical Department of Cardiology and Angiology, First Faculty of Medicine and General Teaching Hospital, Prague, Czech Republic

${ }^{8}$ Kerckhoff Heart and Lung Center, Bad Nauheim, Germany

${ }^{9}$ Division of Pulmonary Diseases, Ludwig Maximilians University, Munich, Germany

${ }^{10}$ Assistance Publique-Hôpitaux de Paris, Service de Pneumologie, Hôpital Bicêtre, Université Paris-Sud, Laboratoire d'Excellence en Recherche sur le Médicament et Innovation Thérapeutique, and Institut National de la Santé et de la Recherche Médicale Unité 999, Le Kremlin-Bicêtre, France 
${ }^{11}$ Department of Pulmonary Circulation and Thromboembolic Diseases, Medical Center of Postgraduate Education, Europejskie Centrum Zdrowia Otwock, Otwock, Poland

${ }^{12}$ Department of Respiratory Medicine, Beijing Institute of Respiratory Medicine, Beijing Chao Yang Hospital, Capital Medical University, Beijing Key Laboratory of Respiratory and Pulmonary Circulation Disorders, Beijing, China

${ }^{13} \mathrm{G}$ lobal Clinical Development, Bayer Pharma AG, Wuppertal, Germany

${ }^{14}$ Department of Medicine, Imperial College London, London, UK

Contributors NHK takes overall responsibility for all aspects of the reliability and freedom from bias of the data presented and their discussed interpretation. NHK, FG, MMH, EM, GS and H-AG were members of the CHEST-1 steering committee and as such contributed to the conception and design of the CHEST-1 study. NHK, AMD'A, FG, EG, MMH, PJ, EM, CN, GS, AT, CW and H-AG recruited and treated patients in the CHEST-1 study. AF performed the statistical analysis. NHK, AMD'A, $F G, E G, M M H, P J, E M, C N, G S, A T, C W, A F, N D$ and $H-A G$ contributed to the conception and design of this paper, the analysis and interpretation of the data and the drafting, critical review and approval of the final manuscript.

Collaborators Full list of CHEST-1 investigators: Argentina: E Perna, Australia: T Williams, Austria: I Lang and C Kaehler, Belgium: M Delcroix and J-L Vachiery, Brazil: J Arakaki, D Waetge and G Meyer, Canada: J Granton, A Hirsch, D Helmersen, S Mehta and L Mielniczuk, China: Z Liu, C Wang, Z Cheng, Z Jing and L Pan, Czech Republic: P Jansa, Denmark: J-E Nielsen-Kudsk, France: G Simonneau, I Franchon, A Chaouat, P De Groote, E Bergot, F Bauer, C Dromer and C-H Marquette, Germany: H-A Ghofrani, M Hoeper, C Neurohr, H Wilkens, G Hoffken, S Rosenkranz, H Wirtz, R Ewert, E Grünig, H Klose, A Filusch and M Held, Italy: AM D'Armini and M Morsolini, Japan: Y Fukumoto, N Tanabe, M Sano, M Hatano, Y Takeda, M Sakuma, T Higo, T Satoh, M Ohe, M Owa, O Okazaki, M Ajioka, M Iwabuchi, M Takata and Y Akashi, Netherlands: A Boonstra, Mexico: C Sanchez Diaz, U Martinez, M Gamba and T Pulido Zamudio, Poland: A Torbicki and P Podolec, Portugal: G Castro, Republic of Korea: S Lee and H Kim, Russia: O Moiseeva and A Chernyavsky, Slovakia: I Simkova, Spain: MA Gomez Sanchez and JA Barbera, Switzerland: R Speich, Taiwan: Y-H Lin, Turkey: G Karabiyikoglu, N Mogulkoc and G Okumus, UK: J Pepke-Zaba, A Peacock and L Howard, USA: R Allen, N Sood, S Chaparro, F Torres, G Heresi, A Zaiman, K Kerr, H Farber and $S$ Hansdottir.

Funding This study was funded by Bayer Pharma AG (Berlin, Germany). Editorial assistance was provided by Adelphi Communications (Bollington, UK), sponsored by Bayer Pharma AG.

Competing interests NHK reports personal fees and non-financial support from Bayer HealthCare Pharmaceuticals; grants and personal fees from Actelion; grants from Gilead, Lung LLC and United Therapeutics. AMD'A reports personal fees from Bayer HealthCare Pharmaceuticals and personal fees from Actelion. FG reports grants, personal fees and non-financial support from Bayer HealthCare Pharmaceuticals and personal fees from Actelion, Lilly, Novartis and Pfizer. EG reports grants, personal fees and non-financial support from Bayer HealthCare Pharmaceuticals, grants and personal fees from Actelion, GSK, Lilly and Pfizer, non-financial support from Alexion and personal fees from Miltenyi, Novartis and United Therapeutics. MMH reports grants, personal fees and non-financial support from Bayer HealthCare Pharmaceuticals and personal fees from Actelion, GSK, Lilly, Novartis and Pfizer. PJ, an investigator for Actelion, reports grants, personal fees and non-financial support from Bayer HealthCare Pharmaceuticals and personal fees from AOP. EM reports personal fees and non-financial support from Bayer HealthCare Pharmaceuticals and personal fees from Actelion, GSK and Pfizer. CN reports grants, personal fees and non-financial support from Bayer HealthCare Pharmaceuticals and personal fees from Actelion, GSK, Novartis and Pfizer. GS reports grants, personal fees and non-financial support from Bayer HealthCare Pharmaceuticals, Actelion, GSK, Lilly and Pfizer and personal fees and non-financial support from Novartis. AT reports grants, personal fees and non-financial support from Bayer HealthCare Pharmaceuticals and grants and personal fees from Actelion, GSK and AOP. CW has nothing to report. AF is an employee of Bayer Pharma AG. ND is an employee of Bayer Pharma AG. H-AG reports grants from Actelion, Bayer HealthCare Pharmaceuticals, Ergonex and Pfizer and personal fees from Actelion, Bayer HealthCare Pharmaceuticals, Ergonex, Gilead, GSK, Merck, Novartis and Pfizer.

Provenance and peer review Not commissioned; externally peer reviewed.

Open Access This is an Open Access article distributed in accordance with the Creative Commons Attribution Non Commercial (CC BY-NC 4.0) license, which permits others to distribute, remix, adapt, build upon this work non-commercially, and license their derivative works on different terms, provided the original work is properly cited and the use is non-commercial. See: http://creativecommons.org/ licenses/by-nc/4.0/

\section{REFERENCES}

1 Dalen JE, Alpert JS. Natural history of pulmonary embolism. Prog Cardiovasc Dis 1975; 17:259-70.

2 Simonneau G, Gatzoulis MA, Adatia I, et al. Updated clinical classification of pulmonary hypertension. J Am Coll Cardiol 2013;62:D34-41.

3 Lang IM, Klepetko W. Chronic thromboembolic pulmonary hypertension: an updated review. Curr Opin Cardiol 2008:23:555-9.

4 Peacock A, Simonneau G, Rubin L. Controversies, uncertainties and future research on the treatment of chronic thromboembolic pulmonary hypertension. Proc Am Thorac Soc 2006:3:608-14.

5 Mayer $E$, Jenkins $D$, Lindner J, et al. Surgical management and outcome of patients with chronic thromboembolic pulmonary hypertension: results from an international prospective registry. J Thorac Cardiovasc Surg 2011;141:702-10.

$6 \mathrm{Kim} \mathrm{NH}$, Delcroix M, Jenkins DP, et al. Chronic thromboembolic pulmonary hypertension. J Am Coll Cardiol 2013;62:D92-9.

7 Galie N, Humbert M, Vachiery JL, et al. 2015 ESC/ERS Guidelines for the diagnosis and treatment of pulmonary hypertension: The Joint Task Force for the Diagnosis and Treatment of Pulmonary Hypertension of the European Society of Cardiology (ESC) and the European Respiratory Society (ERS): Endorsed by: Association for European Paediatric and Congenital Cardiology (AEPC), International Society for Heart and Lung Transplantation (ISHLT). Eur Heart J 2016;37:67-119.

8 Galiè N, Hoeper MM, Humbert M, et al. Guidelines for the diagnosis and treatment of pulmonary hypertension: The Task Force for the Diagnosis and Treatment of Pulmonary Hypertension of the European Society of Cardiology (ESC) and the European Respiratory Society (ERS), endorsed by the International Society of Heart and Lung Transplantation (ISHLT). Eur Heart J 2009;30:2493-537.

9 Jenkins D, Mayer E, Screaton N, et al. State-of-the-art chronic thromboembolic pulmonary hypertension diagnosis and management. Eur Respir Rev 2012;21:32-9.

10 Pepke-Zaba J, Delcroix M, Lang I, et al. Chronic Thromboembolic Pulmonary Hypertension (CTEPH): results from an International Prospective Registry. Circulation 2011;124:1973-81.

11 Bonderman D, Skoro-Sajer N, Jakowitsch J, et al. Predictors of outcome in chronic thromboembolic pulmonary hypertension. Circulation 2007;115:2153-8.

12 Condliffe R, Kiely DG, Gibbs JS, et al. Improved outcomes in medically and surgically treated chronic thromboembolic pulmonary hypertension. Am J Respir Crit Care Med 2008;177:1122-7.

13 Freed DH, Thomson BM, Berman $M$, et al. Survival after pulmonary thromboendarterectomy: effect of residual pulmonary hypertension. J Thorac Cardiovasc Surg 2011;141:383-7.

14 Thistlethwaite PA, Kemp A, Du L, et al. Outcomes of pulmonary endarterectomy for treatment of extreme thromboembolic pulmonary hypertension. I Thorac Cardiovasc Surg 2006;131:307-13.

15 Jaïs $X$, D'Armini $A M$, Jansa $P$, et al. Bosentan for treatment of inoperable chronic thromboembolic pulmonary hypertension: BENEFiT (Bosentan Effects in iNopErable Forms of chronlc Thromboembolic pulmonary hypertension), a randomized, placebo-controlled trial. J Am Coll Cardiol 2008;52:2127-34.

16 Suntharalingam J, Treacy CM, Doughty NJ, et al. Long-term use of sildenafil in inoperable chronic thromboembolic pulmonary hypertension. Chest 2008;134:229-36.

17 Follmann M, Griebenow N, Hahn MG, et al. The chemistry and biology of soluble guanylate cyclase stimulators and activators. Angew Chem Int Ed Engl 2013;52:9442-62.

18 Schermuly RT, Stasch JP, Pullamsetti SS, et al. Expression and function of soluble guanylate cyclase in pulmonary arterial hypertension. Eur Respir J 2008;32:881-91.

19 Stasch JP, Pacher P, Evgenov OV. Soluble guanylate cyclase as an emerging therapeutic target in cardiopulmonary disease. Circulation 2011;123:2263-73.

20 Stasch JP, Evgenov OV. Soluble guanylate cyclase stimulators in pulmonary hypertension. Handb Exp Pharmacol 2013:218:279-313.

21 Ghofrani HA, D'Armini AM, Grimminger F, et al. Riociguat for the treatment of chronic thromboembolic pulmonary hypertension. N Engl J Med 2013;369: 319-29.

22 Conole D, Scott LJ. Riociguat: first global approval. Drugs 2013;73:1967-75.

23 Jenkins DP, Biederman A, D'Armini AM, et al. Operability assessment in CTEPH: lessons from the CHEST-1 study. J Thorac Cardiovasc Surg 2016;152:669-74.e3.

24 Condliffe R, Kiely DG, Gibbs JS, et al. Prognostic and aetiological factors in chronic thromboembolic pulmonary hypertension. Eur Respir J 2009;33:332-8.

25 Saouti N, de Man F, Westerhof N, et al. Predictors of mortality in inoperable chronic thromboembolic pulmonary hypertension. Respir Med 2009;103:1013-19.

26 Simonneau G, D'Armini A, Ghofrani HA, et al. Riociguat for the treatment of chronic thromboembolic pulmonary hypertension (CTEPH): 1-year results from the CHEST-2 long-term extension study. Chest 2013;144:1023A.

27 Humbert M. Pulmonary arterial hypertension and chronic thromboembolic pulmonary hypertension: pathophysiology. Eur Respir Rev 2010;19:59-63. 